\title{
Os Papas e José Saramago: vários olhares e uma única preocupação
}

\author{
The Popes and José Saramago: various looks and a care \\ Los Papas y José Saramago: diferentes miradas y un cuidado
}

Maria Irene da Fonseca e Sál

\begin{abstract}
Resumo
Cartas Encíclicas abordando o tema da qualidade de vida do ser humano no mundo têm sido escritas. Recentemente, o Papa Francisco escreveu a Carta Encíclica Laudato Si': sobre o cuidado da casa comum. Com este gesto, o Papa Francisco faz uso de seu poder como autoridade máxima da Igreja Católica Apostólica Romana para tentar sensibilizar a humanidade para a deterioração da qualidade de vida humana e a degradação social. Preocupação idêntica tinha o escritor português José Saramago. Em vários de seus romances e em muitas de suas falas está presente a preocupação com o mundo e com o rumo da humanidade. Assim, o tema do estudo diz respeito ao olhar dos Papas e de Saramago sobre o mundo contemporâneo e o objetivo é o de identificar semelhanças entre a fala das Encíclicas e a fala de José Saramago, a partir do estudo de sua obra. A pesquisa é qualitativa em que são consideradas e analisadas publicações relativas ao cuidado com o planeta em que vivemos. É pesquisa exploratória por buscar proporcionar maior familiaridade com o tema, com vistas a torná-lo mais explícito. A pesquisa conclui que apesar dos diversos olhares, há uma única preocupação: a reflexão sobre a qualidade de vida da humanidade.
\end{abstract}

Palavras-chave: Cartas Encíclicas. Humanidade. José Saramago. Moral. Ética.

\begin{abstract}
Encyclical Letters addressing the issue of human quality of life in the world have been written. Recently, Pope Francisco wrote the encyclical Laudato Si ': on the care of the common home. With this gesture, the Pope Francisco uses his power as supreme authority of the Roman Catholic Church to try to sensitize humanity to the deterioration of the human quality of life and social degradation. Same concern was the Portuguese writer José Saramago. In several of his novels and many of his lines is present concern for the world and the course of humanity. Thus, the theme of the study concerns the look of the Popes and Saramago about the contemporary world and the goal is to identify similarities between speech of encyclicals and speech of José Saramago, from the study of his work. The research is qualitative as they are considered and analyzed publications relating to the care of the planet we live on. It is exploratory research by seeking to provide greater familiarity with the subject, in order to make it more explicit. The research concludes that despite different views, there is only one concern: a reflection on the quality of life of humanity.
\end{abstract}

Keywords:Encyclical Letters. Humanity. José Saramago. Moral. Ethics.

\section{Resumen}

Cartas Encíclicas que abordan el tema de la calidad de vida humana en el mundo se han escrito.

\begin{tabular}{|c|c|}
\hline \multirow{3}{*}{ 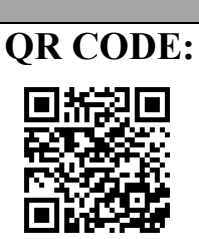 } & Acesse este artigo online \\
\hline & $\begin{array}{l}\text { Website: } \\
\text { http://www.revistas.ufg.br/index.php/ci }\end{array}$ \\
\hline & $\begin{array}{l}\text { DOI: } \\
\text { http://dx.doi.org/10.5216/c\&i.v19i1.372 } \\
78\end{array}$ \\
\hline
\end{tabular}
Recientemente, el Papa Francisco escribió la encíclica Laudato $\mathrm{Si}$ ': en el cuidado del hogar común. Con este gesto, el Papa Francisco usa su poder como autoridad suprema de la Iglesia Católica Romana para tratar de sensibilizar a la humanidad al deterioro de la calidad de vida humana y la

\footnotetext{
${ }^{1}$ Doutorado em Ciência da Informação pela Universidade Federal do Rio de Janeiro (UFRJ), mestrado em Engenharia de Sistemas e Computação pela UFRJ, graduação em Matemática Modalidade Informática pela UFRJ. Brasil, Rio de Janeiro, Rio de Janeiro. E-mail: mariairene@facc.ufrj.br
}

Comun. \& Inf., Goiânia, GO, v. 19, n. 1, p. 123-141, jan./jun. 2016 
degradación social. Igual preocupación era el escritor portugués José Saramago. En varias de sus novelas y muchos de sus líneas está presente la preocupación por el mundo y el curso de la humanidad. Por lo tanto, el tema del estudio se refiere a la apariencia de los Papas y Saramago sobre el mundo contemporáneo y la meta es identificar similitudes entre el habla y el lenguaje de las encíclicas de José Saramago, a partir del estudio de su obra. La investigación es cualitativa ya que se consideran $\mathrm{y}$ analizan las publicaciones relacionadas con el cuidado del planeta en que vivimos. Es una investigación exploratoria, tratando de proporcionar una mayor familiaridad con el tema, con el fin de hacerlo más explícito. La investigación concluye que a pesar de los diferentes puntos de vista, no hay más que una preocupación: una reflexión sobre la calidad de vida de la humanidad.

Palabras clave: Encíclicas. Humanidad. José Saramago. Moral. Ética.

\section{INTRODUÇÃO}

Muito se tem falado do cuidado com o mundo em que vivemos. Ambientalistas, ecologistas, economistas e outros profissionais vêm alertando a humanidade para a escassez dos recursos naturais do planeta, para as alterações/mudanças provocadas pelo mau uso, para a necessidade de controle sobre a disponibilidade e o cuidado com a qualidade de vida dos seres humanos na época atual e no futuro.

Também a Igreja Católica Apostólica Romana tem se posicionado. Cartas Encíclicas abordando o tema da qualidade de vida do ser humano no mundo têm sido escritas. Recentemente, o Papa Francisco escreveu a Carta Encíclica Laudato Si': sobre o cuidado da casa comum. Com este gesto, o Papa Francisco faz uso de seu poder como Bispo de Roma e autoridade máxima da Igreja Católica Apostólica Romana para tentar sensibilizar a humanidade para a deterioração da qualidade de vida humana e a degradação social. "Nesta encíclica, pretendo especialmente entrar em diálogo com todos acerca da nossa casa comum." (PAPA FRANCISCO, 2015, p.4). "O urgente desafio de proteger a nossa casa comum inclui a preocupação de unir toda a família humana na busca de um desenvolvimento sustentável e integral, pois sabemos que as coisas podem mudar." (PAPA FRANCISCO, 2015, p.13).

Preocupação idêntica tinha o escritor português José Saramago. Em vários de seus romances e em muitas de suas falas está presente a preocupação com o mundo e com o rumo da humanidade.

Em 5 de junho de 1973, Saramago escreve no Diário de Lisboa um texto cujo título é: Qual mundo é a nossa casa? “Celebra-se hoje o Dia Mundial do Ambiente o que permitiria abrir a porta deste comentário com algumas alusões escolhidas àqueles outro comentários em que nos batemos (pacificamente, claro) por ares mais limpos, por águas mais puras, por mais silêncio, por mais harmonia de vida, enfim. [...] Primeiramente, caberia uma meditação sobre o tema deste dia, que é, com alguma sentimentalidade, "o mundo é a nossa casa"” (SARAMAGO, 2014b, p.137-138). 
Saramago, já falecido, em 1973 usa expressão semelhante à utilizada pelo Papa Francisco em 2015: casa. Como estamos cuidando da nossa casa e como estamos vivendo na nossa casa são as questões.

Portanto, o tema da pesquisa diz respeito ao olhar dos Papas e de Saramago sobre o mundo contemporâneo e o objetivo é o de identificar semelhanças entre a fala das Encíclicas e a fala de José Saramago, a partir do estudo de sua obra.

De modo a tratar o tema proposto, o trabalho, do ponto de vista da forma de abordagem do problema, vale-se da pesquisa qualitativa em que são consideradas e analisadas publicações relativas ao cuidado com o planeta em que vivemos. Quanto ao objetivo é pesquisa exploratória por buscar proporcionar maior familiaridade com o tema, com vistas a torná-lo mais explícito.

Neste tipo de pesquisa, o pesquisador é o principal instrumento da coleta de dados. Os métodos da pesquisa qualitativa são subjetivos, indutivos, usam teoria fundamentada, empregam instrumentos que produzem informação linguística (como observações), os resultados são reportados em frases e o pesquisador está envolvido.

\section{DESENVOLVIMENTO}

Em 9 de outubro de 1998, a Academia Sueca comunicou a atribuição do Prémio Nobel da Literatura a José Saramago “que, com parábolas portadoras de imaginação, compaixão e ironia torna constantemente compreensível uma realidade fugidia" (NOBEL PRIZE, 1998). Assim, a Academia Sueca atribui o termo "parábola" aos romances de Saramago.

Segundo o Dicionário Koogan/Houaiss (1997), parábola é “Comparação desenvolvida em pequeno conto, no qual se encerra uma verdade, um ensinamento." Portanto, há que buscar nos romances de Saramago as verdades (pois não existe uma única) e os ensinamentos (que também são vários).

Saramago disse em 1986: "Sou ateu com uma atitude religiosa e vivo muito em paz." (AGUILERA, 2010, p.36). Assim, como Jesus, gostava de falar por parábolas. Na Bíblia Sagrada, os quatro evangelistas afirmam que Jesus usava parábolas para transmitir ensinamentos. "E Jesus falou para eles muita coisa com parábolas [...] (MATEUS, 1990, p.1255) "Jesus lhes perguntou: "Vocês não compreendem essa parábola?" (MARCOS, 1990, p.1286). "Então Jesus contou-lhes esta parábola [...]" (LUCAS, 1990, p.1334). "Jesus contou-lhes essa parábola, mas eles não entenderam o que Jesus queria dizer.” (JOÃO, 1990, 
p.1369). Nas palavras dos evangelistas percebe-se que as parábolas nem sempre alcançavam o seu propósito, ou seja, nem sempre o povo e os discípulos entendiam os ensinamentos que Jesus pretendia lhes passar. Da mesma forma, as parábolas (os romances) de Saramago, nem sempre são bem entendidos ou não alcançam o objetivo que o escritor teve ao pensá-los e escrevê-los. É o próprio Saramago que diz:

Escrever é traduzir. Sempre o será. Mesmo quando estivermos a utilizar a nossa própria língua. Transportamos o que vemos e o que sentimos (supondo que ver e sentir, como em geral os entendemos, sejam algo mais que as palavras com que nos vem sendo relativamente possível expressar o visto e o sentido...) para um código convencional de signos, a escrita, e deixamos às circunstâncias e aos acasos da comunicação a responsabilidade de fazer chegar à inteligência do leitor, não tanto a integridade da esperiência que nos propusemos transmitir (inevitalmente parcelar em relação à realidade de que se tinha alimentado), mas uma sombra, ao menos, do que no fundo do nosso espírito sabemos bem ser intraduzível [...] (SARAMAGO,2011, p.53-54).

Por sua vez, o Papa Francisco é bastante claro e conclama a humanidade:

Lanço um convite urgente a renovar o diálogo sobre a maneira como estamos a construir o futuro do planeta. Precisamos de um debate que nos una a todos, porque o desafio ambiental, que vivemos, e as suas raízes humanas dizem respeito e têm impacto sobre todos nós. O movimento ecológico mundial já percorreu um longo e rico caminho, tendo gerado numerosas agregações de cidadãos que ajudaram na consciencialização. Infelizmente, muitos esforços na busca de soluções concretas para a crise ambiental acabam, com frequência, frustrados não só pela recusa dos poderosos, mas também pelo desinteresse dos outros. As atitudes que dificultam os caminhos de solução, mesmo entre os crentes, vão da negação do problema à indiferença, à resignação acomodada ou à confiança cega nas soluções técnicas. Precisamos de nova solidariedade universal (PAPA FRANCISCO, 2015, p.13)

Em vários momentos, a Igreja Católica tem-se manifestado sobre os cuidados com o mundo.

\subsection{ENCÍCLICA PACEM IN TERRIS}

Em abril de 1963, o Papa João XXIII, através da Carta Encíclica Pacem in Terris, dirigida ao clero, à comunidade católica e "a todas as pessoas de boa vontade" (PAPA JOÃO XXIII, 1963), falava principalmente dos direitos e das relações dos seres humanos, criticava o crescente desenvolvimento de armamento, ao mesmo tempo em que regeitava a guerra e transmitia uma proposta de paz.

Costuma-se justificar essa corrida ao armamento aduzindo o motivo de que, nas circunstâncias atuais, não se assegura a paz senão com o equilíbrio de forças: se uma comunidade política se arma, faz com que também outras comunidades políticas porfiem em aumentar o próprio armamento. E, se uma comunidade política produz armas atômicas dá motivo a que outras nações se empenhem em preparar semelhantes armas, com igual poder destrutivo. 
O resultado é que os povos vivem em terror permanente, como sob a ameaça de uma tempestade que pode rebentar a cada momento em avassaladora destruição. Já que as armas existem e, se parece difícil que haja pessoas capazes de assumir a responsabilidade das mortes e incomensuráveis destruições que a guerra provocaria, não é impossível que um fato imprevisível e incontrolável possa inesperadamente atear esse incêndio. Além disso, ainda que o imenso poder dos armamentos militares afaste hoje os homens da guerra, entretanto, a não cessarem as experiências levadas a cabo com uns militares, podem elas pôr em grave perigo boa parte da vida sobre a terra (PAPA JOÃO XXIII, 1963).

Portanto, o Papa João XXIII refletia:

A todos os homens de boa vontade incumbe a imensa tarefa de restaurar as relações de convivência humana na base da verdade, justiça, amor e liberdade: as relações das pessoas entre si, as relações das pessoas com as suas respectivas comunidades políticas, e as dessas comunidades entre si, bem como o relacionamento de pessoas, famílias, organismos intermédios e comunidades políticas com a comunidade mundial (PAPA JOÃO XXIII, 1963).

No que diz respeito a armamento, Saramago alerta:

Espalhados por 64 países, existem mais de 110 milhões de minas antipessoais, à espera de que alguém lhes vá pôr o pé em cima. Não têm esperado em vão: em cada ano, por causa delas, morrem ou ficam mutiladas 24000 pessoas, isto é, em cada vinte minutos rebenta uma mina. Só em Angola há mais de 12 milhões de minas ativas enterradas, uma para cada habitante, e ainda ficariam muitas minas para lhe arrancarem a outra perna. As minas são montadas em fábricas de armamento (tanto legais como ilegais) por operários especializados que, como é natural, cobram o seu salário. Esses operários conhecem perfeitamente $\mathrm{o}$ destino $\mathrm{e}$ as consequências dos produtos que lhes saem das mãos. Não tenho notícia de qualquer greve de protesto nessas fábricas (SARAMAGO, 2011, p. 23).

Com essa preocupação e motivação, em 2009, Saramago começa a escrever o livro: Alabardas, alabardas, espingardas, espingardas que ficaria inconcluso com o seu falecimento em 18 de junho de 2010 aos oitenta e sete anos. Nesse livro, Saramago denuncia: "Todos os países, quaisquer que sejam, capitalistas, comunistas ou fascistas, fabricam, vendem e compram armas, e não é raro que as usem contra os seus próprios naturais. [...] É assim, mas não o deveria ser. [...] Não temos outro mundo" (SARAMAGO, 2014a, p. 29). Assim,Saramago termina seus dias no mundo provocando os seus leitores,através de um romance que apresenta um cenário de grande conflito moral, a fazerem uma reflexão sobre a apatia moral e um retorno à ética, tomando como argumento a produção e o uso de armas."Toda a vida tenho estado à espera de ver uma greve de braços caídos numa fábrica de armamento, inutilmente esperei, porque tal prodígio nunca aconteceu nem acontecerá" (SARAMAGO, 2009, p.103).

Em $O$ Caderno 2, Saramago fala de armas, guerra e paz: 
Culturalmente é mais fácil mobilizar os homens para a guerra que para a paz. Ao longo da história, a Humanidade sempre foi levada a considerar a guerra como o meio mais eficaz de resolução de conflitos, e sempre os que governaram se serviram dos breves intervalos de paz para a preparação das guerras futuras. Mas foi sempre em nome da paz que todas as guerras foram declaradas. É sempre para que amanhã vivam pacificamente os filhos que hoje são sacrificados os pais...(SARAMAGO, 2009, p.80).

Há que pensar nesse paradoxo proposto por Saramago.

\subsection{CARTA APOSTÓLICA OCTOGESIMA ADVENIENS}

Em 1971, o Papa Paulo VI dirigiu a Carta Apostólica Octogesima Adveniens ao presidente do Conselho dos Leigos e da Pontifícia Comissão "Justiça e Paz". Nessa carta, o Papa faz referência à problemática ecológica, descrevendo-a como consequência direta da atividade descontrolada do ser humano.

À medida que o horizonte do homem assim se modifica, a partir das imagens que se selecionam para ele, uma outra transformação começa a fazer-se sentir, conseqüência tão dramática quanto inesperada da atividade humana. De um momento para outro, o homem toma consciência dela: por motivo da exploração inconsiderada da natureza, começa a correr o risco de destruí-la e de vir a ser, também ele, vítima dessa degradação. Não só já o ambiente material se torna uma ameaça permanente, poluições e lixo, novas doenças, poder destruidor absoluto; é mesmo o quadro humano que o homem não consegue dominar, criando assim, para o dia de amanhã, um ambiente global, que poderá tornar-se-lhe insuportável. Problema social de envergadura, este, que diz respeito à inteira família humana(PAPA PAULO VI, 1971).

O Papa Paulo VI também alerta para novos problemas sociais.

Baseada na pesquisa tecnológica e na transformação da natureza, a industrialização prossegue sem parar o seu caminho, dando mostras de um poder criador incessante. Ao mesmo tempo que certas empresas se desenvolvem e se concentram, outras morrem ou deslocam-se, criando-se, assim, novos problemas sociais: desemprego profissional ou regional, reconversão e mobilidade das pessoas, adaptação permanente dos trabalhadores, disparidade das condições nos diversos ramos industriais. Uma competição desmedida, que utiliza os meios modernos de publicidade, lança sem cessar novos produtos e procura aliciar o consumidor; e então, as antigas instalações industriais, ainda em funcionamento, ficam inutilizadas. E, assim, enquanto vastíssimas camadas da população não podem ainda satisfazer as suas necessidades primárias, emprega-se $\mathrm{o}$ engenho em criar as necessidades supérfluas. Poder-se-á, pois, perguntar, com toda a razão, se, apesar de todas as suas conquistas, o homem não está voltando contra si próprio os frutos da sua atividade(PAPA PAULO VI, 1971).

Neste sentido, Saramago publica, em 2000, o romance A Caverna. Esse romance “

[...] viria efectivamente a contrastar a absolutização do mercado no símbolo do centro

Comun. \& Inf., Goiânia, GO, v. 19, n. 1, p. 123-141, jan./jun. 2016 
comercial e do consumidor no lugar do cidadão com uma família de oleiros artesanais que acaba por conseguir subtrair-se à lógica concentracionista do neoliberalismo" (LOPES, 2010, p.111-112). É uma parábola social que fala da alienação da humanidade e da recusa de aceitação da situação por uma família de oleiros. No entanto, reforça a visão pessimista do escritor, que ganhara o Prêmio Nóbel em 1998, num mundo abandonado pela razão. É um romance que fala de mudanças e de como as mudanças são percebidas e assimiladas pelo ser humano:

[...] são os tempos que mudam, são os velhos que em cada hora envelhecem um dia, é o trabalho que deixou de ser o que havia sido, e nós que só podemos ser o que fomos, de repente percebemos que já não somos necessários no mundo, se é que alguma vez o tinhamos sido antes, mas acreditar que o éramos parecia bastante, parecia suficiente, e era de certa maneira eterno pelo tempo que a vida durasse [...] (SARAMAGO, 2000, p. 106-107).

Apesar de pessimista e cético em relação à humanidade, Saramago (2000, p.264) ainda nutre uma pequena esperança: “à espera de que a rotação do mundo voltasse a pôr todas as coisas nos seus lugares, sem esquecer algumas que até agora ainda não conseguiram encontrar sítio."

\subsection{CARTA ENCÍCLICA REDEMPTOR HOMINIS}

O Papa João Paulo II abordou o tema da destruição do ser humano e do ambiente em diferentes documentos. Em 1979, ele endereçou a Encíclica Redemptor Hominis à comunidade Católica e "a todos os homens de boa vontade". Nela, ele alerta a humanidade para a própria ação do ser humano, nem sempre útil para a sociedade, e apresenta o ser humano ameaçado pela produção do próprio ser humano.

O homem de hoje parece estar sempre ameaçado por aquilo mesmo que produz; ou seja, pelo resultado do trabalho das suas mãos e, ainda mais, pelo resultado do trabalho da sua inteligência e das tendências da sua vontade. Os frutos desta multiforme actividade do homem, com muita rapidez e de modo muitas vezes imprevisível, passam a ser, não tanto objecto de «alienação», no sentido de que são simplesmente tirados àquele que os produz, quanto, ao menos parcialmente e num círculo consequente e indirecto dos seus efeitos, tais frutos se voltam contra o próprio homem. Eles passam então, de facto, a ser dirigidos, ou podem ser dirigidos contra o homem. E nisto assim parece consistir o capítulo principal do drama da existência humana contemporânea na sua mais ampla e universal dimensão (PAPA JOÃO PAULO II, 1979).

E prossegue, como o Papa Paulo VI, questionando o verdadeiro valor do progresso:

O progresso da técnica e o desenvolvimento da civilização do nosso tempo, que é marcado aliás pelo predomínio da técnica, exigem um proporcional desenvolvimento também da vida moral e da ética. E no entanto este último, infelizmente, parece ficar sempre atrasado. [...] este progresso não pode 
deixar de gerar multíplices inquietações. Uma primeira inquietação diz respeito à questão essencial e fundamental: Este progresso, de que é autor e fautor o homem, torna de facto a vida humana sobre a terra, em todos os seus aspectos, « mais humana »? Torna-a mais « digna do homem »? Não pode haver dúvida de que, sob vários aspectos, a torna de facto tal. Esta pergunta, todavia, retorna obstinadamente e pelo que respeita àquilo que é essencial em sumo grau: se o homem, enquanto homem, no contexto deste progresso, se torna verdadeiramente melhor, isto é, mais amadurecido espiritualmente, mais consciente da dignidade da sua humanidade, mais responsável, mais aberto para com o outros, em particular para com os mais necessitados e os mais fracos, e mais disponível para proporcionar e prestar ajuda a todos (PAPA JOÃO PAULO II, 1979).

Em 1995, Saramago publica Ensaio sobre a Cegueira, um romance alegórico pessimista que inaugura um novo ciclo do autor em que ele vai narrar a irracionalidade do mundo contemporâneo que está a serviço do mercado, do lucro e da competição e da perda da razão do ser humano com seus instintos. "Estamos rodeados de imagens que nos mostram que o mundo está mal, mas nós estaremos bem pior no dia em que nos tivermos acostumado tanto à violência que a consideremos natural - ou cultural, se assim preferirem. Precisamos de uma outra maneira de olhar as imagens que nos mostram a realidade, já que com a realidade, ela própria, não ousamos enfrentar-nos. (SARAMAGO, 2011, p. 93).

Talvez o que melhor caracterize o romance de Saramago Ensaio sobre a Cegueira seja o termo "desconcertos do mundo". A cegueira alcança a todos, com exceção de uma única personagem que procura se manter racional. De inicio vem o internamento num manicômio dos que perderam a visão, mas em seguida todos ficam cegos e a cidade entra num estado de degradação total, com todo tipo de exploração: física, sexual, econômica, moral,.. Desta forma, Saramago nos apresenta a sociedade em que vivemos, com todos os tipos de exploração.

Saramago tenta trazer o leitor para a reflexão quando diz: "Penso que não cegámos, penso que estamos cegos. Cegos que vêem, cegos que, vendo, não vêem" (SARAMAGO, 1995, p.310).

O Papa João Paulo II já alertava para a crise moral: "O nosso século tem sido até agora um século de grandes calamidades para o homem, de grandes devastações, não só materiais, mas também morais, ou melhor, talvez sobretudo morais"(PAPA JOÃO PAULO II, 1979) e ressaltava a importância da Organização das Nações Unidas (ONU), um esforço para definir e estabelecer os invioláveis direitos do homem. Saramago corrobora e enfatiza que:

O funcionamento do mundo deixou de ser o completo mistério que foi, as alavancas do mal encontram-se à vista de todos, para as mãos que as manejam já não há luvas bastantes que lhes escondam as manchas de sangue. Deveria portanto ser fácil a qualquer um escolher entre o lado da 
verdade e o lado da mentira, entre o respeito humano e o desprezo pelo outro, entre os que são pela vida e os que estão contra ela. Infelizmente as coisas nem sempre se passam assim. O egoísmo pessoal, o comodismo, a falta de generosidade, as pequenas cobardias do quotidiano, tudo isto contribui para essa perniciosa forma de cegueira mental que consiste em estar no mundo e não ver o mundo, ou só ver dele o que, em cada momento, for susceptível de servir os nossos interesses. Em tais casos não podemos desejar senão que a consciência nos venha sacudir urgentemente por um braço e nos pergunte à queima-roupa: "Aonde vais? Que fazes? Quem julgas tu que és?" Uma insurreição das consciências livres é o que necessitaríamos. Será ainda possível? (SARAMAGO, 2009, p. 207).

Portanto, Saramago afirma que é do despertar das consciências dos seres humanos que o mundo precisa.

\subsection{CARTA ENCÍCLICA CARITAS IN VERITATE}

O Papa Bento XVI, em 2009, encaminhou a Carta Encíclica Caritas in Veritate à toda a Comunidade Católica e "a todos os homensde boa vontade" (PAPA BENTO XVI, 2009) falando sobre o desenvolvimento humano integralna caridade e na verdade. Nela, o Papa Bento XVI reflete sobre a Carta EncíclicaPopulorum Progressio, do Papa Paulo VI, e alerta que as causas do subdesenvolvimento não são primariamente de ordem material, convidando-nos a procurá-las noutras dimensões do homem. "A sociedade cada vez mais globalizada torna-nos vizinhos, mas não nos faz irmãos. A razão, por si só, é capaz de ver a igualdade entre os homens e estabelecer uma convivência cívica entre eles, mas não consegue fundar a fraternidade" (PAPA BENTO XVI, 2009). Bento XVI afirma que a realidade do mundo em 2009 é bem pior do que a relatada por Paulo VI em 1967.Ele denuncia a situação do mundo contemporâneo:

Cresce a riqueza mundial em termos absolutos, mas aumentam as desigualdades. Nos países ricos, novas categorias sociais empobrecem e nascem novas pobrezas. Em áreas mais pobres, alguns grupos gozam duma espécie de superdesenvolvimento dissipador e consumista que contrasta, de modo inadmissível, com perduráveis situações de miséria desumanizadora. Continua « o escândalo de desproporções revoltantes ». Infelizmente a corrupção e a ilegalidade estão presentes tanto no comportamento de sujeitos económicos e políticos dos países ricos, antigos e novos, como nos próprios países pobres. No número de quantos não respeitam os direitos humanos dos trabalhadores, contam-se às vezes grandes empresas transnacionais e também grupos de produção local. As ajudas internacionais foram muitas vezes desviadas das suas finalidades, por irresponsabilidades que se escondem tanto na cadeia dos sujeitos doadores como na dos beneficiários. Também no âmbito das causas imateriais ou culturais do desenvolvimento e do subdesenvolvimento podemos encontrar a mesma articulação de responsabilidades: existem formas excessivas de protecção do conhecimento por parte dos países ricos, através duma utilização demasiado rígida do direito de propriedade intelectual, especialmente no campo da saúde; ao 
mesmo tempo, em alguns países pobres, persistem modelos culturais e normas sociais de comportamento que retardam o processo de desenvolvimento. (PAPA BENTO XVI, 2009).

Ele fala da crise econômica, dos sistemas de segurança e previdência do ponto de vista social, da mobilidade laboral associada à generalizada desregulamentação, do ecletismo cultural, da fome e do respeito pela vida.E enfatiza a aplicação da caridade nas possíveis soluções:

As grandes novidades, que o quadro actual do desenvolvimento dos povos apresenta, exigem em muitos casos novas soluções. Estas hão-de ser procuradas conjuntamente no respeito das leis próprias de cada realidade e à luz duma visão integral do homem, que espelhe os vários aspectos da pessoa humana, contemplada com o olhar purificado pela caridade. Descobrir-se-ão então singulares convergências e concretas possibilidades de solução, sem renunciar a qualquer componente fundamental da vida humana (PAPA BENTO XVI, 2009).

Alguns dos romances de Saramago descrevem eras de transformação, que na visão dele representam mais perdasque ganhos para o ser humano.

Em 2002, Saramago publica O Homem Duplicado, cerca de dois anos após a publicação do romance $A$ Caverna, que mantem a preocupação com o mundo globalizado, com a sociedade do exibicionismo, com a cultura do descartável e com a alienação do ser humano. Enquanto no romance A Caverna, a critica estava no centro comercial e no ser humano consumidor, no romance $O$ Homem Duplicado é apresentado um ser humano incapaz de se ver no próximo, em que o 'eu'fica ameaçado pela presença do 'outro'. Portanto, enquanto o mundo se globaliza através de uma cultura geral (moda, música, costumes ...), o ser humano não se vê no seu igual, ou melhor não aceita o outro igual a si.É uma metáfora para a alienação do ser humano. Pode-se usar a mesma roupa, as mesmas marcas, ouvir e cantar a mesma música, fazer as mesmas coisas, ter os mesmos hábitos..., mas ter a mesma aparência não é aceito. Nesse romance, não há lugar para a solidariedade que pode transformar a realidade. Pelo contrário, fica explicita a agressividade da humanidade num mundo em que cada vez mais sedeterioram as relações entre os seres humanos.Nesse mundo, relatado por Saramago, não há lugar para a caridade. E Saramago discorre sobre a globalização de sentimentos:

Deixando agora de lado se deveríamos ou não envergonhar-nos de ser a espécie a que pertencemos aquilo que é, ao menos envergonhemo-nos das nossas apatias, das nossas indiferenças, das nossas cumplicidades tácitas ou abertas, das nossas penosas cobardias disfarçadas de neutralidade. Já que os poderes do mundo se mostram tão empenhados em globalizar-nos, globalizemo-nos nós por nossa conta...(SARAMAGO, 2011, p.233). 
Assim, num mundo em que a razão não considera a ética e em que o ser humano não considera seu semelhante, Saramago (2002, p. 103) lembra que: "O caos é uma ordem por decifrar".

\subsection{CARTA ENCÍCLICA LAUDATO SI’}

Nesta Carta Encíclica, o Papa Francisco (2015) faz uma revisão dos documentos escritos por seus antecessores, desde o Papa João XXIII, de forma a mostrar que há mais de cinquenta anos a Igreja Católica vem se procupando com a "casa comum" e lembra que: "O nosso corpo é constituído pelos elementos do planeta; o seu ar permite-nos respirar, e a sua água vivifica-nos e restaura-nos" (PAPA FRANCISCO, 2015). Ele diz que as publicações dos Papas são oriundas da reflexão de cientistas, filósofos, teólogos e organizações sociais, incluindo as preocupações desenvolvidas por outras religiões. Fala de São Francisco de Assis, inspiração para seu pontificado: "Nele se nota até que ponto são inseparáveis a preocupação pela natureza, a justiça para com os pobres, o empenhamento na sociedade e a paz interior" (PAPA FRANCISCO, 2015), resssaltando a simplicidade e a harmonia em que ele vivia com os outros, com a natureza e consigo mesmo.

No capítulo I ele dicorre sobre "O que está acontecendo com a nossa casa" (PAPA FRANCISCO, 2015).

Em primeiro, fala da poluição e das mudanças climáticas e afirma que: “A terra, nossa casa, parece transformar-se cada vez mais num imenso depósito de lixo. [...] Ainda não se conseguiu adoptar um modelo circular de produção que assegure recursos para todos e para as gerações futuras e que exige limitar, o mais possível, o uso dos recursos não-renováveis, moderando o seu consumo, maximizando a eficiência no seu aproveitamento, reutilizando e reciclando-os" (PAPA FRANCISCO, 2015). Saramago, mais enfático, corrobora e denuncia:

Poluir, isto é, sujar, conspurcar, envenenar, intoxicar, é tão inevitável para o homem como produzir sombra se está ao alcance de um foco luminoso. [...] outras sombras se alinhariam ao lado daquela, mas os nomes dessas (guerra, fome, racismo, intolerância, e mais, e mais) já todos nos habituámos, e por isso protestamos tão pouco. Porque a verdade é que o homem suporta muito melhor as coisas do que os nomes delas, enquanto a eles não se habitua. Depois suporta tudo.

Em regra, vem a estabelecer-se um equilíbrio que permite ir vivendo entre a ameaça da extinção total e a total erradicação dessa ameaça. Sabiamente, toleram os fabricantes de armas as campanhas a favor da paz, e este é o exemplo mais direto que destes equilíbrios poderíamos dar. Também a poluição não será eliminada. Há-de igualmente estabelecer-se um equilíbrio que permita a venda lucrativa dos processos de a combater até aquele nível que, por um lado, a torne tolerável, e, por outro, não ponha em perigo a prosperidade da indústria que proporcionará os meios para esse combate.

Comun. \& Inf., Goiânia, GO, v. 19, n. 1, p. 123-141, jan./jun. 2016 
[...] Punir delitos é fácil, se há suficiente decisão para isso, mas evitá-los, preveni-los, liquidá-los à nascença, requer outro saber e outra firmeza (SARAMAGO, 2014b, p. 64-65).

Portanto, a visão de Saramago é de descrença na humanidade. No entanto, o Papa Francisco ainda confiante no ser humano, apela para a consciência da humanidade. Sobre o aquecimento do sistema climático, ele diz: "A humanidade é chamada a tomar consciência da necessidade de mudanças de estilos de vida, de produção e de consumo, para combater este aquecimento ou, pelo menos, as causas humanas que o produzem ou acentuam." (PAPA FRANCISCO, 2015). E alertasobre quem serão os mais atingidos:

Muitos pobres vivem em lugares particularmente afectados por fenómenos relacionados com o aquecimento, e os seus meios de subsistência dependem fortemente das reservas naturais e dos chamados serviços do ecossistema como a agricultura, a pesca e os recursos florestais. Não possuem outras disponibilidades económicas nem outros recursos que lhes permitam adaptar-se aos impactos climáticos ou enfrentar situações catastróficas, e gozam de reduzido acesso a serviços sociais e de protecção (PAPA FRANCISCO, 2015).

Saramago é mais enfático e descrente do ser humano:

[...] Mas o homem é o ser racional entre todos os seres que constituem a população animal da Terra. Pela razão que em si habita, libertou-se da sujeição cega à natureza e afeiçoou-a às suas necessidades. Errou muitas vezes, emendou-se e insistiu no caminho, e hoje, vivida uma história de milénios, acha-se, ao que parece, diante da possibilidade de desaparecer da face da Terra, não, como chegou a imaginar-se, através do desastre nuclear, do envenenamento radiativo, mas simplesmente, absurdamente, porque comeu tudo quanto havia para comer, ao mesmo tempo que sujava a mesa e a toalha...

[...] Já hoje centenas de milhões de seres humanos não comem quanto deveriam, embora os alimentos existentes bastassem para tal, se fossem produzidos e distribuídos em estrito acordo com as necessidades da humanidade. Estes males só poderão agravar-se com o aumento da população e com o desperdício das riquezas naturais, mas isto não há de significar que a "recessão demográfica" por alguns desejada se faça em termos de discriminação entre povos ricos e pobres. Pelo princípio dos vasos comunicantes, o lado "cheio" tende a preencher o lado "vazio", porventura esvaziado para que isso mesmo aconteça...(SARAMAGO, 2014b, p.40-41).

Assim, ele faz uma prospecção sobre o futuro da humanidade, ao mesmo tempo que chama a atenção para as regras do mercado mundial.

Em segundo, o Papa Francisco discorre sobre a questão da água: “A água potável e limpa constitui uma questão de primordial importância, porque é indispensável para a vida humana e para sustentar os ecossistemas terrestres e aquáticos.” (PAPA FRANCISCO, 2015).Além de prever "que o controle da água por grandes empresas mundiais se transforme em uma das principais fontes de conflito deste século"(PAPA FRANCISCO, 2015), ele, 
novamente, alerta para os que são mais afetados pela qualidade e escassez da água, consequencias do desperdício e da poluição: "Um problema particularmente sério é o da qualidade da água disponível para os pobres, que diariamente ceifa muitas vidas. Entre os pobres, são frequentes as doenças relacionadas com a água, incluindo as causadas por microorganismos e substâncias químicas" (PAPA FRANCISCO, 2015). Mais uma vez, o Papa conclama a sociedade a se preocupar com os mais pobres. Saramago, inconformado com a pobreza no Mundo, exclama: “A pobreza é uma humilhação". (AGUILERA, 2010, p. 490) e corrobora com a visão do Papa, falando do que percebe dessa realidade:

Esse rio da minha infância, o Almonda, já é um esgoto, e dá-me tanta pena... A acção do homem muda tudo. Mas o pior é que, ao mudar, mata. O tempo urge. Há uns anos parecia que o aquecimento global nunca nos iria afectar, mas já está aí. Se se derreterem os gelos da Gronelândia, o nível do mar subirá sete centímetros, desaparecerão cidades... O planeta está em perigo. Por exemplo, não me surpreenderia que no futuro a água fosse motivo de guerra(AGUILERA, 2010, p. 497).

E nesse cenário, os mais afetados sempre são os pobres. E Saramago ainda alerta: "O planeta está sofrendo um saque de seus recursos materiais. Como não temos outra despensa do que a própria Terra, essa exploração tende a esgotar nossas reservas naturais. O homem encarrega-se de se destruir a si próprio" (AGUILERA, 2010, p. 496).

Em terceiro, o Papa Francisco fala da perda da biodiversidade e denuncia: “Anualmente, desaparecem milhares de espécies vegetais e animais, que já não poderemos conhecer [..]" (PAPA FRANCISCO, 2015) e proclama:

É preciso investir muito mais na pesquisa para se entender melhor o comportamento dos ecossistemas e analisar adequadamente as diferentes variáveis de impacto de qualquer modificação importante do meio ambiente. Visto que todas as criaturas estão interligadas, deve ser reconhecido com carinho e admiração o valor de cada uma, e todos nós, seres criados, precisamos uns dos outros. Cada território detém uma parte de responsabilidade no cuidado desta família, pelo que deve fazer um inventário cuidadoso das espécies que alberga a fim de desenvolver programas e estratégias de protecção, cuidando com particular solicitude das espécies em vias de extinção (PAPA FRANCISCO, 2015).

Saramago segue na mesma linha e denuncia os desvarios da humanidade, enquanto enfatiza a falta de opcões no mundo para os mais pobres:

Todos os dias desaparecem espécies animais e vegetais, idiomas, ofícios. Os ricos são cada vez mais ricos e os pobres cada vez mais pobres [...] A ignorância expande-se de forma aterradora. Temos um gravíssimo problema na redistribuição da riqueza. A exploração chegou a requintes diabólicos. As multinacionais dominam o mundo. Não sei se são as sombras ou as imagens que nos ocultam a realidade. Podemos discutir sobre o tema infinitamente, o certo é que perdemos capacidade crítica para analisar o que se passa no mundo. Daí que pareça que estamos encerrados na caverna de Platão. 
Abandonamos a nossa responsabilidade de pensar, de actuar. Convertemonos em seres inertes sem a capacidade de indignação, de inconformismo e de protesto que nos caracterizou durante muitos anos.[...] Está claro que tudo tem de morrer, mas há gente que, enquanto vive, tem a construir a sua própria felicidade, e esses são eliminados. Perdem a batalha pela sobrevivência, não suportaram viver segundo as regras do sistema. Vão-se como vencidos, mas com a dignidade intacta, simplesmente dizendo que se retiram porque não querem este mundo." (SARAMAGO, 2009, p. 107-108).

Em quarto,o Papa explora o tema derioração da qualidade de vida humana e degradação social:

Entre os componentes sociais da mudança global, incluem-se os efeitos laborais dalgumas inovações tecnológicas, a exclusão social, a desigualdade no fornecimento e consumo da energia e doutros serviços, a fragmentação social, o aumento da violência e o aparecimento de novas formas de agressividade social, o narcotráfico e o consumo crescente de drogas entre os mais jovens, a perda de identidade.", enquanto aponta para o isolamento que é gerado pelo mundo digital e apela para "A verdadeira sabedoria, fruto da reflexão, do diálogo e do encontro generoso entre as pessoas [...]" (PAPA FRANCISCO, 2015).

É a barbárie denunciada através do romance parábola Ensaio sobre a Cegueira por Saramago. É o fim da razão da humanidade. Saramago credita a responsabilidade da situação do mundo ao próprio ser humano: “[...] o pior inimigo do homem é, evidentemente, o mesmo homem... (SARAMAGO, 2014b, p.126).

Em quinto, o Papa fala da desigualdade planetária enfatizando que "O ambiente humano e o ambiente natural degradam-se em conjunto;"(PAPA FRANCISCO, 2015) e sinaliza que "A desigualdade não afecta apenas os indivíduos mas países inteiros, e obriga a pensar numa ética das relações internacionais"(PAPA FRANCISCO, 2015). Assim, enquanto discorre sobre os problemas dos pobres e em especial as desigualdades entre o Norte e o Sul, ele alerta que: "É preciso revigorar a consciência de que somos uma única família humana. Não há fronteiras nem barreiras políticas ou sociais que permitam isolar-nos e, por isso mesmo, também não há espaço para a globalização da indiferença” (PAPA FRANCISCO, 2015).O mundo é formado por diferentes sistemas envolvendo o poder, principalmente o político e e o econômico. Sempre foi assim. Saramago denuncia a indiferença dos sistemas financeiros e a apatia da sociedade:

A gravíssima crise económica e financeira que está convulsionando o mundo traz-nos a angustiante sensação de que chegámos ao final de uma época sem que se consiga vislumbrar o quê e como será o que virá de seguida.

Que fazemos nós, que assistimos, impotentes, ao avanço esmagador dos grandes potentados económicos e financeiros, loucos por conquistar mais e mais dinheiro, mais e mais poder, com todos os meios legais ou ilegais ao seu alcance, limpos ou sujos, regulares ou criminais?

[...] O que se está a passar é, em todos os aspectos, um crime contra a humanidade e desde esta perspectiva deve ser analisado nos fóruns públicos 
e nas consciências. Não é exagero. Crimes contra a humanidade não são apenas os genocídios, os etnocídios, os campos de morte, as torturas, os assassinatos selectivos, as fomes deliberadamente provocadas, as contaminações maciças, as humilhações como método repressivo da identidade das vitimas. Crime contra a humanidade é também o que os poderes financeiros e económicos, com a cumplicidade efectiva ou tácita dos governos, friamente perpetraram contra milhões de pessoas em todo mundo, ameaçadas de perder o que lhes resta, a sua casa e as suas poupanças, depois de terem perdido a única e tantas vezes escassa fonte de rendimento, quer dizer, o seu trabalho" (SARAMAGO, 2009, p. 241).

No entanto, alerta que: "Pior do que um mundo com guerras, com fome e com doenças só um mundo de homens todos iguais, pacíficos e saudáveis." (SARAMAGO, 2011, p. 234). Com esta frase, Saramago lembra que as adversidades e as diferenças são saudáveis. É a partir das adversidades que o ser humano se sente impelido a buscar novas soluções e alternativas. Se não há desafios, prospera a estagnação. As diferenças culturais são enriquecedoras. É a discussão do local versus o global. É a crítica ao mundo globalizado, todos iguais, sem identidade, sem raízes... Também está implícito o espírito de indignação. O ser humano não deve se acomodar à situação, mas indignar-se quando for necessário e explora o sentimento de dignidade no ser humano: “[...] dignidade, isso que não se vende nem se deixa comprar, o que é no ser humano o grau supremo." (SARAMAGO, 2009, p. 222).

Em sexto, o Papa pontua as fraquezas das reações e faz a critica: "A submissão da política à tecnologia e à economia demonstra-se na falência das cúpulas mundiais sobre o meio ambiente"(PAPA FRANCISCO, 2015). E discorre sobre a degradação ambiental e a degradação humana e ética. Saramago também fala das vozes que denunciam, mas que não criam movimentos positivos para a humanidade:

De vez em quando, e com uma regularidade que poderia levar a acreditar em revezamento premeditado, surgem vozes de alarme contra a rapidez com que se vão consumindo as reservas naturais do planeta, agravada por aquilo a que passou a chamar-se, maltusianamente, "explosão demográfica".

[...] Talvez haja, de facto, gente a mais, e a poluição, em todas as suas formas, ganha certamente proporções de cataclismo. Quanto aos recursos da Terra, se nos lembrarmos de que nada se pode tirar donde não haja, não custa a acreditar que se caminha para uma pauperização das fontes de energia e de subsistência que permitiram, até agora, melhor ou pior, a vida dos homens. (SARAMAGO, 2014b, p. 39-40).

Saramago ainda discorre sobre as características do ser humano: "O próprio do homem é a inconstância nos propósitos e nos actos, sempre a contradizerem-se de uma hora para outra" (SARAMAGO, 2009, p.116). Uma coisa é o discurso e outra coisa é a prática.

Em sétimo, o Papa reflete sobre a diversidade de opiniões. Enquanto uns defendem o progresso, outros vêm o ser humano como uma ameaça ao ecossistema mundial. O Papa Francisco lembra que:

Comun. \& Inf., Goiânia, GO, v. 19, n. 1, p. 123-141, jan./jun. 2016 
A esperança convida-nos a reconhecer que sempre há uma saída, sempre podemos mudar de rumo, sempre podemos fazer alguma coisa para resolver os problemas. Todavia parece notar-se sintomas dum ponto de ruptura, por causa da alta velocidade das mudanças e da degradação, que se manifestam tanto em catástrofes naturais regionais como em crises sociais ou mesmo financeiras, uma vez que os problemas do mundo não se podem analisar nem explicar de forma isolada (PAPA FRANCISCO, 2015).

Saramago, por sua vez, diz que "Tranquilizemo-nos, porém: o homem é o animal mais resistente da Terra, porque se nutre de um alimento invisível chamado esperança" (SARAMAGO, 2014b, p.76). E aponta a sua esperança: "E era essa minha pobre e única esperança de que a humanidade ainda fosse capaz de mudar de caminho, de rumo, de destino" (SARAMAGO, 2009, p. $103)$.

\section{CONSIDERAÇÕES FINAIS}

Saramago escreveu seus romances indignado com a situação do mundo contemporâneo. Neles, ele apela para a refleção sobre o retorno à razão, à ética e à solidariedade. Em suas falas, em entrevistas, apontamentos e textos publicados, Saramago se mantem pessimista quanto à ação do homem no mundo. “[...] o mundo será igual ao que é hoje, como é igual, hoje, ao que era há quatrocentos anos. Refiro-me à intolerância e à crueldade, não à exploração do espaço nem aos computadores..."(SARAMAGO, 2011, p. 131). Aguilera fala sobre a obra de Saramago e a preocupação dele com os desvarios da humanidade:

Saramago estimava que "a literatura é o que faz inevitavelmente pensar". Concebeu o romance como um exercício de ação intelectual, um método para programar cenários verbais de pensamento e, por conseguinte, um veículo para refletir. Suas fabulações pensavam e faziam pensar, até se postularem, metaforicamente, como uma espécie de ensaios com personagens. [...] De modo que sua obra se ergue como um monumental marco narrativo empenhado em meditar sobre o mal e o erro contemporâneos, atento aos desvios do ser humano, preocupado no fim das contas com as múltiplas variantes de desumanidade que nos fustigam. (AGUILERA, 20014, p.74).

Da mesma forma, os papas, através de suas Cartas Encíclicas, vem tentando sensibilizar a humanidade para os problemas do mundo e as ações do ser humano. O Papa Paulo VI alerta para as mudanças pelas quais o mundo está permanentemente passando:

Importa saber equacionar os problemas sociais, postos pela economia moderna - condições humanas de produção, equidade nas permutas de bens e na repartição das riquezas, significado das crescentes necessidades de consumo e compartilha das responsabilidades - num contexto mais amplo, de civilização nova. Nas atuais mutações, tão profundas e tão rápidas, cada dia o homem se descobre como algo novo e interroga-se a si mesmo, acerca do sentido do seu próprio ser e da sua sobrevivência coletiva (PAPA PAULO VI, 1971).

Comun. \& Inf., Goiânia, GO, v. 19, n. 1, p. 123-141, jan./jun. 2016 
Há que pensar nas palavras do Papa Paulo VI, em sua carta Octogesima Adveniens

(1971):

Difundido pelos modernos meios de informação e pela solicitação de saber e de consumo mais espalhada, o progresso tornou-se uma ideologia onipresente. No entanto, em nossos dias uma dúvida se levanta, tanto sobre o seu valor, como sobre as suas possibilidades de êxito. O que significa, realmente, esta busca inexorável de um progresso, que parece escapar-se sempre que se pensa tê-lo alcançado?

Qualque que seja o progresso, se é progresso, não poderia ir contra a humanidade. "O progresso beneficia só uma minoria" (SARAMAGO, 2000, apud AGUILERA, 2010, p.157). Não deveria estar o progresso aliado a uma consciência moral? João Paulo II (1979) denuncia a incapacidade dos sistemas de poder de resolver as injustiças sociais:

A amplitude do fenómeno põe em questão as estruturas e os mecanismos financeiros, monetários, produtivos e comerciais, que, apoiando-se em diversas pressões políticas, regem a economia mundial: eles demonstram-se como que incapazes quer para reabsorver as situações sociais injustas, herdadas do passado, quer para fazer face aos desafios urgentes e às exigências éticas do presente. Submetendo o homem às tensões por ele mesmo criadas, dilapidando, com um ritmo acelerado, os recursos materiais e energéticos e comprometendo o ambiente geofísico, tais estruturas dão azo a que se estendam incessantemente as zonas de miséria e, junto com esta, a angústia, a frustração e a amargura.

Ele responsabiliza o próprio ser humano pelo que acontece no mundo:

O nosso século tem sido até agora um século de grandes calamidades para o homem, de grandes devastações, não só materiais, mas também morais, ou melhor, talvez sobretudo morais. Não é fácil, certamente, comparar épocas e séculos sob este aspecto, uma vez que isso depende também dos critérios históricos que mudam. Não obstante, prescindido muito embora de tais comparações, importa verificar que até agora este século foi um tempo em que os homens prepararam para si mesmos muitas injustiças e sofrimentos. Este processo terá sido decididamente entravado? (JOÂO PAULO II, 1979).

E, o Papa Francisco, sempre preocupado com os mais indefesos, avisa que a própria terra está indefesa e necessita de cuidados urgentes: "Por isso, entre os pobres mais abandonados e maltratados, conta-se a nossa terra oprimida e devastada [...] (PAPA FRANCISCO, 2015).

Saramago, pessimista quanto ao sucesso das mensagens papais, mas atento ao que se passa no mundo, escreve sobre a mensagem A Paz é Possível, do Papa Paulo VI no Dia Mundial da Paz em 1973:

[...] já que não se acredita que por palavras de um papa cessem as guerras, ainda será notar como são justas certas observações do chefe da Igreja, na verdade atento a subtilezas que ultrapassam a simples alternativa guerra/paz.[...] E agora é o mais ilustre intérprete de uma mensagem de mansidão que vem dizer que a paz não deve ser confundida "com a fraqueza, não só física mas moral, com a renúncia ao verdadeiro direito e à justiça equitativa, com a fuga perante o risco e o sacrifício, com a resignação receosa e submetida ao domínio de outrem, na aceitação da própria escravidão" (SARAMAGO, 2014b, p.208-209). 
Assim, em toda a obra de Saramago, percebe-se a critica e a indignação com a crise financeira, a crise econômica, a crise política, a crise religiosa, a crise ambiental, a crise energética, mas principalmente a crise moral que segundo ele está no âmago do ser humano. "[...] a própria humanidade se encarregará de destruir o mundo e destruir-se a si mesma" (SARAMAGO, 2011, p. 47). E faz uma prelação sobre as diferentes intolerâncias, iniciando pela intolerância racista, que poderão levar a humanidade ao seu fim:

Não é ousado prever um tempo em que os ódios racistas hão de parecer realmente monstruosos, não humanos, um tempo que incluirá o nosso num longuíssimo período de barbárie caracterizado por intolerâncias várias, em que são exemplos mais flagrantes de um comportamento histórico geral a intolerância racial, a intolerância religiosa e a intolerância política.

Se não soubermos ainda eliminar completamente este "vício" moral, psicológico e político que pretende dividir a espécie humana em grupos, privilegiados uns, degradados outros, temos cada vez mais clara noção de que tal caminho conduziria a humanidade ao seu próprio suicídio, após um infinito de crimes. (SARAMAGO, 2014b, p.71).

Portanto, pode-se concluir que o esforço dos Papas, em especial do Papa Francisco em sua Carta Encíclica Laudato Si', em conclamar a humanidade a cuidar de si, do outro e da natureza é endossado pela obra que Saramago produziu. Saramago, ateu, porém um homem reflexivo e descrente do ser humano, apela para a retomada da razão da humanidade. $\mathrm{O}$ mundo e a sociedade está à vista de todos. Cabe a cada um escolher que ações efetuar e que lado tomar. "Nós diríamos que precisamente por causa da recusa de examinar os erros passados e pô-los a claro é que, infalivelmente, recaímos em novos erros, com a esperança, sempre confirmada, de que o futuro venha, se não desculpá-los, pelo menos a caridosamente os cobrir com o véu do esquecimento... (SARAMAGO, 2014b, p. 143). Assim, Saramago conclama o ser humano a refletir sobre alteridade e pertencimento. Tudo alerta que o tempo está se esgotando. Já não há tempo para desculpas e esquecimentos. Saramago, através de sua obra, chama a humanidade a ver o mundo. Assim, as palavras da Encíclica Laudato Sí' devem servir para reflexão, para afastar " [...] essa perniciosa forma de cegueira mental que consiste em estar no mundo e não ver o mundo..." (SARAMAGO, 2009, p. 207).

\section{REFERÊNCIAS}

AGUILERA, F. G. Um livro inconcluso, uma vontade consistente. In: SARAMAGO, J. Alabardas, alabardas,espingardas, espingardas. São Paulo: Companhia das Letras, 2014.

AGUILERA, F.G. José Saramago nas suas palavras. 2. ed. Alfragide, Portugal: Caminho, 2010.

Bento XVI, Papa.Carta Encíclica Caritas in Veritate. Vaticano, 2009. Disponível em:

$<$ http://w2.vatican.va/content/benedict-xvi/pt/encyclicals/documents/hf_benxvi_enc_20090629_caritas-in-veritate.html>. Acesso em: 01 ago. 2015. 
BIBLIA, N. T. João. Português. Bíblia Sagrada: edição pastoral. Tradução de Ivo Storniolo e Euclides Balancin. São Paulo: Edições Paulinas, 1990. cap. 10, vers.6.

BIBLIA, N. T. Lucas. Português. Bíblia Sagrada: edição pastoral. São Paulo: Edições Paulinas, 1990. cap. 15 , vers. 3 .

BIBLIA, N. T. Marcos. Bíblia Sagrada: edição pastoral. São Paulo: Edições Paulinas, 1990. cap. 4, vers. 13.

BIBLIA, N. T. Mateus. Bíblia Sagrada: edição pastoral. São Paulo: Edições Paulinas, 1990. cap. 13, vers. 3.

Francisco, Papa. Carta Encíclica Laudato si': sobre o cuidado da casa comum. Vaticano, 2015.

Disponível em: $<$ http://w2.vatican.va/content/francesco/pt/encyclicals/documents/papa-

francesco_20150524_enciclica-laudato-si.html $>$. Acesso em: 01 ago. 2015.

João Paulo II, Papa. Carta Encíclica Redemptor Hominis. Vaticano, 1979. Disponível em:

$<$ http://w2.vatican.va/content/john-paul-ii/pt/encyclicals/documents/hf_jp-

ii_enc_04031979_redemptor-hominis.html>. Acesso em: 01 ago. 2015.

João XXIII, Papa. Pacem in Terris. Vaticano, 1963. Disponível em

$<\mathrm{http} / /$ w2.vatican.va/content/john-xxiii/pt/encyclicals/documents/hf j-

xxiii_enc_11041963_pacem.html>. Acesso em: 03 ago. 2015.

KOOGAN/HOUAISS. Enciclopédia e Dicionário Ilustrado. Rio de Janeiro: Edições Delta, 1997.

LOPES, J.M.Biografia - José Saramago. Lisboa, Portugal: Guerra \& Paz, 2010.

NOBEL PRIZE. ORG. Disponível em

$<$ http://www.nobelprize.org/nobel_prizes/literature/laureates/1998/press-po.html>. Acesso em: 03 ago. 2015.

Paulo VI, Papa. A Paz é Possível. Vaticano, 1972. Disponível em: <http://w2.vatican.va/content/paul$\mathrm{vi} / \mathrm{pt} / \mathrm{messages} /$ peace/documents/hf_p-vi_mes_19721208_vi-world-day-for-peace.html $>$. Acesso em: 03 ago. 2015.

Paulo VI, Papa. Octogesima Adveniens. Vaticano, 1971. Disponível em:

$<$ http://w2.vatican.va/content/paul-vi/pt/apost_letters/documents/hf_p-vi_ap1_19710514_octogesimaadveniens.html>. Acesso em: 03 ago. 2015.

SARAMAGO, J. A caverna. São Paulo: Companhia das Letras, 2000.

SARAMAGO, J. Alabardas, alabardas, espingardas, espingardas. São Paulo: Companhia das Letras, 2014a.

SARAMAGO, J. Ensaio sobre a cegueira. São Paulo: Companhia das Letras, 1995.

SARAMAGO, J. O Caderno 2. Alfragide: Editorial Caminho, 2009.

SARAMAGO, J. O homem duplicado. São Paulo: Companhia das Letras, 2002.

SARAMAGO, J. Os apontamentos. 4. ed. Lisboa: Porto Editora, $2014 \mathrm{~b}$.

SARAMAGO, J. Cadernos de Lanzarote: Diário V. Alfragide: Caminho, 2011.

Recebido em: 19/08/2015

Aceito em: 30/09/2015

Publicado em: 11/10/2016 